\title{
ARTIGOS
}

\section{O ESTADO, O PODER, O SOCIALISMO DE POULANTZAS COMO UM CLÁSSICO MODERNO ${ }^{1}$}

\author{
Bob Jessop
}

\begin{abstract}
RESUMO
Poulantzas afirmou que O Estado, o poder, o socialismo, sua última grande obra, completou a teoria do tipo capitalista de Estado que Marx e Engels deixaram incompleta. Embora essa imodesta mas provocativa afirmação certamente mereça discussão, ela não pode ser avaliada seriamente em um curto ensaio. Em vez disso, neste artigo desenvolver-se-ão quatro argumentos principais. Em primeiro lugar, Poulantzas elaborou uma contribuição maior para a teoria do tipo capitalista de Estado que vai bem além das análises marxistas mais convencionais e contrasta marcadamente com estudos sobre o Estado na sociedade capitalista. Em segundo lugar, ele desenvolveu uma abordagem mais ampla para o Estado como uma relação social que sustenta o tipo capitalista de Estado, diversos estados nas formações sociais capitalistas e a condição estatal de modo geral. Em terceiro lugar, ele adotou ambas abordagens em suas próprias análises teóricas e históricas. Em quarto lugar, sua análise da forma atual do tipo capitalista de Estado era altamente presciente, com o "estatismo autoritário" muito mais evidente agora que quando ele notou os traços de seu surgimento nos anos 1970. Após desenvolver esses argumentos, o artigo também indica algumas limitações básicas da abordagem de Poulantzas para a teoria materialista do Estado, concluindo que O Estado, o poder, o socialismo deveria ser percebido como um clássico moderno.
\end{abstract}

PALAVRAS-CHAVE: Poulantzas; teoria marxista do Estado; tipo capitalista de Estado; estatismo autoritário.

\section{INTRODUÇÃO}

Poulantzas afirmou que $O$ Estado, o poder, o socialismo, sua última grande obra, completou a teoria do tipo capitalista de Estado que Marx e Engels deixaram incompleta (POULANTZAS, 1978b) ${ }^{2}$. Embora essa imodesta mas provocativa afirmação certamente mereça discussão, ela não pode ser avaliada seriamente em um curto ensaio. Em vez disso, desenvolverei quatro argumentos principais. Em primeiro lugar, Poulantzas elaborou uma contribuição maior para a teoria do tipo capitalista de Estado que vai bem além das análises marxistas mais convencionais e contrasta marcadamente com estudos sobre o Estado na sociedade capitalista. Em segundo lugar, ele desenvolveu uma abordagem mais ampla para o Estado como uma relação social que sustenta o tipo

\footnotetext{
1 Este artigo, cujo original é em inglês, teve uma versão anterior publicada em alemão (JESSOP, 2006a). Sua tradução para o português foi feita graças à gentil autorização do autor. Tradução de Gustavo Biscaia de Lacerda e revisão da tradução de Álvaro Bianchi.

2 Para a explicação do próprio Poulantzas sobre essa incompletude, cf. Poulantzas (1973, "Introduction”, p. 19-23).
}

capitalista de Estado, diversos estados nas formações sociais capitalistas e a condição estatal [statehood] de modo geral. Em terceiro lugar, ele adotou ambas abordagens em suas próprias análises teóricas e históricas. Em quarto lugar, sua análise da forma atual do tipo capitalista de Estado era altamente premonitório, com o "estatismo autoritário” muito mais evidente agora que quando ele notou os traços de seu surgimento nos anos 1970. Após desenvolver esses argumentos, também indicarei algumas limitações básicas da abordagem de Poulantzas à teoria materialista do Estado, concluindo que $O$ Estado, o poder, o socialismo deveria ser percebido como um clássico moderno.

\section{O TIPO CAPITALISTA DE ESTADO}

Mesmo se não for a última palavra na teoria marxista do Estado, o derradeiro livro de Poulantzas certamente foi uma exitosa culminação de seus esforços para desenvolver uma abordagem forma-analítica [form-analytical ${ }^{3}$ ] do tipo capitalista de Estado baseado em uma cuidadosa

\footnotetext{
3 A expressão “form-analytical” significa literalmente "forma-analítica”, o que, obviamente, não existe em português e cuja melhor tradução seria “análise formal”. Entretanto, a
} 
leitura dos clássicos marxistas. Tanto seu primeiro grande texto sobre o Estado capitalista (Poder político e classes sociais, de 1968 (POULANTZAS, 1973)) quanto o seu último texto (O Estado, o poder, o socialismo, de 1978 (POULANTZAS, 1978a)) procuram responder a crucial questão analítica inicialmente proposta por Pashukanis: "por que, para assegurar sua dominação política, a burguesia dispõe de um aparato tão específico como o Estado capitalista - o moderno Estado representativo, o Estado nacional-popular de classe" (explicitamente POULANTZAS, 1978a, p. 49; cf. implicitamente POULANTZAS, 1974, p. 123). Em ambos os casos, Poulantzas argumentou que, enquanto o governo direto de classe deveria ser percebido como ilegítimo mesmo se fosse possível (algo excluído pela competição econômica e pela rivalidade política entre os capitais individuais), o moderno Estado representativo oferece uma estrutura flexível para unificar os interesses políticos de longo prazo de um bloco no poder de outra forma fissíparos, para desorganizar as classes subalternas e para assegurar o consentimento das massas populares.

Ao desenvolver essa abordagem em Poder político e classes sociais, Poulantzas examinou o tipo capitalista de Estado em três passos principais. Em primeiro lugar, inspirado pelo marxismo althusseriano, ele argumentou que a separação institucional entre economia e política, típica do modo capitalista de produção, permitiu e requereu uma teoria autônoma da região política. Em segundo lugar, dadas essas possibilidade e necessidade, ele esboçou conceitos básicos de uma teoria jurídico-política para descrever a matriz institucional do tipo capitalista de Estado: um Estado territorial soberano hierarquicamente organizado, coordenado centralizadamente, baseado no império da lei [rule of law] e, em sua forma idealtípica "normal", combinado com a democracia burguesa. Essa forma do regime político é orientada para sujeitos políticos como cidadãos

fim de respeitar o estilo intelectual do autor, preferimos uma tradução mais literal, nesse caso. Adotamos o mesmo critério para outras expressões que seguem o mesmo padrão, como “crisis-tendencies” ("tendências-crise”) (nota do tradutor) individuais mais que como membros de classes opostas e, assim, distingue a realidade objetiva da exploração econômica e do poder de classe. Em terceiro lugar, remanejando a análise gramsciana da hegemonia, ele argumentou que, dada essa matriz institucional e os sujeitos políticos individualizados, a dominação política depende da capacidade da classe dominante de promover um projeto hegemônico que vincule os interesses individuais ao interesse nacional-popular, que também serve aos interesses de longo prazo da classe capitalista e dos seus aliados do bloco no poder.

O Estado, o poder, o socialismo também possui uma estrutura tripartite. Ele vai passo a passo de proposições gerais sobre o Estado, passando por uma teoria do tipo capitalista de Estado, para uma teoria mais concreto-complexa do tipo de Estado na presente fase do capitalismo - tudo cuidadosamente articulado de modo a ir de proposições gerais sobre a produção em geral, para a divisão capitalista social do trabalho e para o presente estágio do capitalismo. Nesse sentido, a última obra de Poulantzas é uma contribuição mais geral para a crítica da Economia Política que não apenas percebe o Estado como um elemento integral na dominação política de classe, como também insiste em seu papel crucial em assegurar importantes condições econômicas e extra-econômicas para a acumulação. Em cada passo de seu argumento, ele também enfatiza a centralidade das lutas e do poder de classe para a natureza e o desenvolvimento do processo de trabalho, das relações sociais de produção e do Estado. Dessa forma, ele também desenvolveu análises "teórico-estratégicas aplicadas” sobre as perspectivas de uma transição democrática para o socialismo democrático (a esse respeito, cf. JESSOP, 1985).

Dito isso, Poulantzas tipicamente combinou dois tipos de análise sobre o Estado capitalista em suas pesquisas teóricas e históricas, pois, tão cedo quanto em Poder político e classes sociais, ele implicitamente distinguiu uma interpretação teórica do tipo capitalista de Estado e reflexões teóricas sobre o Estado em sociedades capitalistas (POULANTZAS, 1973, parte II, cap. 2-4). A primeira modalidade começa com uma análise mais abstrato-simples da adequação formal de um determinado tipo de Estado em uma formação social capitalista pura, argumentando que sua forma 
tipicamente torna problemática sua funcionalidade e examina como e em qual extensão as práticas políticas podem superar tais problemas em períodos e conjunturas específicos (JESSOP, 1982; 1990). Em contraste, a outra modalidade focaliza em termos relativamente concreto-complexos os "estados de fato existentes" em sociedades que são dominadas pelas relações capitalistas de produção, examina se suas atividades são funcionalmente adequadas para a acumulação de capital e para a dominação política de classe e investiga como essa adequação funcional é obtida (ou não) em conjunturas específicas por meio de estratégias e políticas públicas específicas promovidas por forças sociais particulares. Em suas pesquisas teóricas, Poulantzas tendeu a privilegiar a análise estratégico-relacional, de modo a identificar a particularidade histórica do tipo capitalista de Estado e a estabelecer uma tipologia e uma periodização de suas várias formas. Essa abordagem é exemplificada em Poder político e classes sociais, As classes sociais no capitalismo de hoje e $O$ Estado, o poder, o socialismo. Em sua obra histórica, entretanto, ele priorizou uma análise estratégico-relacional da variável equilíbrio de forças, de modo a mostrar como as lutas políticas de classes e seus resultados são mediados e condensados por meio de formas institucionais específicas em períodos, estágios e conjunturas particulares, inobstante se tais formas correspondem ao tipo capitalista de Estado ${ }^{4}$. Essa abordagem é ilustrada pelas análises do absolutismo e dos três modelos históricos contrastantes de desenvolvimento do Estado capitalista em $\mathrm{Po}$ der político e classes sociais; em suas análises fortemente periodizadas de regimes de exceção seus surgimentos, suas consolidações, suas tendências-crise [crisis-tendencies] e seus colapsos -, em Fascismo e ditadura e A crise das ditaduras, e em vários comentários sobre as disjunções estruturais e as descontinuidades temporais em estados capitalistas efetivamente existentes ao longo de sua obra.

\footnotetext{
4 O improdutivo debate entre Poulantzas e Miliband envolveu um "diálogo entre surdos", pois, enquanto Poulantzas privilegiou uma análise do tipo capitalista de Estado, Miliband focalizou os estados capitalistas efetivamente existentes. Mesmo quando Poulantzas analisou os últimos, ele relacionou suas formas e funções àquelas do tipo capitalista de Estado.
}

Enquanto ambas as abordagens provaram-se produtivas para seus propósitos específicos, não está claro se Poulantzas desejou combiná-las de modo a produzir uma interpretação completa e coerente do Estado capitalista ou se elas simplesmente constituem diferentes abordagens para diferentes objetos analíticos, não totalmente reconciliáveis. Enquanto ambas as abordagens são claramente compatíveis com sua afirmação de que o Estado é uma relação social, a primeira prioriza forma-análises [form-analysis] e a segunda privilegia o estudo das forças sociais. Além disso, faltam em toda a sua obra teórica e histórica pesquisas mais detalhadas sobre o crucial papel de mediação das formas institucionais e organizacionais da política e suas implicações estratégico-relacionais para o equilíbrio de de forças. Se ele as tivesse elaborado, seria muito mais fácil avaliar se as duas abordagens podem, como eu suspeito, ser adequadamente reconciliadas.

\section{O ESTADO COMO UMA RELAÇÃO SO- CIAL}

Ao explorar esses temas em $O$ Estado, o poder, o socialismo e em pesquisas anteriores, Poulantzas elaborou a fundação da sua distinta versão da teoria marxista do Estado, i. e., a afirmação de que o Estado é uma relação social. Ele explicitamente rejeitou a visão de que o Estado é uma entidade de direito próprio - seja um instrumento dócil, seja um sujeito racional. Em vez disso, "como o 'capital', ele é [...] uma relação de forças ou, mais precisamente, a condensação material de tal relacionamento entre as classes $e$ as frações de classe, da forma como ela é expressão no Estado em uma forma necessariamente específica" (POULANTZAS, 1978a, parte II, p. 1). Por analogia com a análise de Marx sobre o capital como uma relação social, essa afirmação pode ser reformulada como segue: o Estado não é uma coisa mas uma relação social entre pessoas, mediada por sua relação com coisas (cf. MARX, 1967, cap. 23); ou, novamente, o Estado não é um sujeito mas uma relação social entre sujeitos mediada pela sua relação com as capacidades do Estado. Mais precisamente, essa abordagem interpreta e explica o poder do Estado (não o aparato do Estado) como uma condensação determinada formalmente [form-determined] da variável equilíbrio de forças nas disputas política e politicamente relevante. 
Para traduzir essa interpretação intuitivamente plausível em análises concreto-complexas de períodos, estágios ou conjunturas políticas específicos, requer-se o estudo de três momentos interrelacionados: 1) a constituição histórica e/ou formal do Estado ${ }^{5}$ como um conjunto institucional complexo com um padrão espaço-temporal específico de "seletividade estratégica estruturalmente inserida"; 2) a organização e a configuração históricas e substantivas das forças políticas em conjunturas específicas e suas estratégias, incluindo sua capacidade para refletir e para responder às seletividades estratégicas inscritas no aparato estatal como um todo; 3) a interação dessas forças nesse terreno estrategicamente seletivo e/ou a uma distância a partir da qual eles perseguem objetivos imediatos ou buscam alterar a balança de forças e/ou transformar o Estado e suas seletividades estratégicas básicas. Ao adotar essa abordagem estratégico-relacional para o poder do Estado, Poulantzas implicitamente rejeitou uma teoria geral do Estado em favor de análises históricas forma-analíticas da reprodução expandida (ou transformação) mediada pela agência da relação do capital. Ele reconheceu que a constituição histórica e formal do Estado não é pré-dada mas resulta de lutas passadas e é também reproduzida (ou transformada) em e por meio de lutas. Ele também se recusou a tratar o equilíbrio de forças como fixo e explorou como ele é modificada por meio de alterações no terreno estratégico-relacional do Estado, da economia e na formação social mais ampla, bem como por meio de mudanças na organização, na estratégia e na tática.

Essa análise da materialidade institucional do Estado em $O$ Estado, o poder, o socialismo esclarece sua particularidade como um terreno de luta política vis-à-vis aquele da luta econômica de classes. Além disso, Poulantzas também vinculou essa nova interpretação relacional do Estado a uma crítica marxista mais ampla e igualmente original da Economia Política. Em particular, ele analisou o processo de trabalho em termos de uma complexa divisão econômica, política e intelectual do trabalho e examinou as classes sociais em termos de sua reprodução estendida, mais que da perspecti-

\footnotetext{
5 Poulantzas discutiu tanto a formação histórica e o funcionamento do Estado capitalista como uma forma híbrida (POULANTZAS, 1973, p. 144-146, 154-156, 161-166, 168183) quanto sua constituição formal como um tipo capitalista de Estado (idem, p. 148-151, 189; parte 4, cap. 3-5).
}

va econômica "estreita" de seu lugar na produção, na distribuição e no consumo. A reprodução estendida das classes sociais envolve relações econômicas, políticas e ideológicas e conduz ao Estado e à divisão do trabalho intelectual-manual bem como ao circuito do capital e das relações de produção não-capitalistas. Poulantzas sempre pôs as relações sociais de produção nesse sentido ampliado e a presença-ausência constitutiva do Estado nessas relações no coração de sua análise da luta de classes. Também devido a isso ele analisou a reprodução social em termos da reprodução das inter-relacionadas condições econômicas, políticas e ideológicas para a acumulação (POULANTZAS, 1974; 1975; 1978a).

\section{A CONTRIBUIÇÃO DE O ESTADO, O PO- DER, O SOCIALISMO}

Poulantzas chegou a essa crucial percepção sobre a natureza relacional do Estado em sua crítica do fascismo, refinou-a em suas reflexões sobre a crise das ditaduras militares do Sul da Europa e desenvolveu-a mais completamente em $O$ Estado, o poder, o socialismo. A parte I desse livro apresenta uma sofisticada interpretação da materialidade institucional do tipo capitalista de Estado que ilumina seus traços mais básicos e seu impacto estrategicamente seletivo sobre as formas e as possibilidades da luta de classes. Poulantzas primeiro mostra que todos os aparatos de Estado (incluindo os aparatos econômicos e repressivos e não apenas os ideológicos) são a expressão quintessencial da separação entre os trabalhos mental e manual; em seguida, ele apresenta as conseqüências disso para a luta política. Na seqüência, ele explora o significado da individualização para as formas da luta política e para as possibilidades de totalitarismo. Ele deriva parte disso de Gramsci, que notou como o moderno Estado democrático, com suas fundações na cidadania individual e em um Estado nacional soberano, encorajou a política normal a assumir a forma de uma luta pela hegemonia nacional-popular. Mas Poulantzas desenvolveu seu tema de uma forma mais profunda e mais abrangente por meio de seu engajamento crítico com as idéias de Foucault sobre a normalização disciplinar do corpo e sobre outras técnicas de poder. Ele também desenvolveu poderosos argumentos sobre os papéis da força e da lei na moldagem do terreno estratégico do tipo capitalista de Estado e sobre como o recurso a elas é moldado por sua vez pela luta de classe. A discussão sobre a seletividade 
estratégica conclui com uma análise inovadora da nação moderna, de seu papel na formação do Estado, de sua sobredeterminação pela luta de classes e do significado das matrizes espaço-temporais que circunscrevem e segmentam o território nacional econômica e politicamente e molda seus ritmos econômico e político.

Tendo esboçado essa estrutura básica para analisar a materialidade institucional do Estado, Poulantzas mostrou como ele opera para modificar e condensar o equilíbrio de forças nas lutas políticas no tipo capitalista de Estado. Ele então continuou a argumentar que esse Estado serve para organizar as classes dominantes e para desorganizar as classes dominadas; mas também pôs grande ênfase na natureza necessariamente fraturada e desunificada do aparato de Estado e em como isso torna problemática a imposição de uma linha estratégica global para o exercício do poder de Estado. Isso é particularmente importante, pois assim ele reconheceu que as classes dominadas e suas lutas estão presentes no próprio sistema estatal bem como estão à distância dele. Isso significou que ele pôde oferecer uma interpretação melhor da natureza relacional do poder enquanto ainda a baseava nas relações sociais de produção e na materialidade institucional do Estado - por meio do que rejeitava a teoria generalizada do poder e da resistência em favor de uma interpretação revolucionária e materialista do poder de classe e de sua sobredeterminação.

Em um terceiro passo analítico, indo em direção ao concreto-complexo em um período particular, Poulantzas analisou a relação cambiante entre as condições econômicas e extra-econômicas de acumulação do capital na fase contemporânea do capitalismo. Aqui ele baseou-se em argumentos de As classes sociais no capitalismo de hoje (POULANTZAS, 1975) para desenvolver quatro temas: 1) as funções econômicas do Estado podem agora ocupar a posição dominante entre as outras funções (com as inevitáveis repercussões sobre suas estruturas e a possibilidade de manutenção de sua hegemonia); 2) os limites entre o econômico e o extra-econômico foram reelaborados, com os previamente elementos extra-econômicos sendo agora vistos como diretamente relevantes para a valorização e para a competitividade; 3 ) isso significa que as intervenções econômicas do Estado são crescentemente focalizadas nas próprias relações sociais de pro- dução e nos esforços para aumentar a produtividade do trabalho, especialmente por meio de uma mais-valia relativa aumentada; 4) mesmo aquelas políticas públicas mais diretamente envolvidas com a reprodução econômica, não obstante terem um caráter essencialmente político e que devem ser conduzidas à luz de seu significado político mais amplo para a manutenção da coesão social em uma sociedade dividida por classes. Essa extensão da intervenção do Estado intensifica as tensões e as fissuras entre diferentes frações do capital e também acentua as desigualdades e as disparidades entre as classes subordinadas e dominantes. $\mathrm{O}$ Estado, portanto, assume algumas das características de um Estado de exceção mas em uma base continuísta e, nesse sentido, ele deve ser visto como a nova forma "democrática" da república burguesa no capitalismo contemporâneo. Isso se deve, de acordo com Poulantzas, ao "intensificado controle do Estado sobre cada esfera da vida sócio-econômica combinado com um declínio radical das instituições da democracia política e com as restrições draconianas e multiformes das assim chamadas liberdades 'formais', cuja realidade, está sendo descoberto agora, está sendo jogada fora” (POULANTZAS, 1978a, p. 203204).

\section{REGIMES DE EXCEÇÃO}

A obra inicial de Poulantzas largamente ignorou dois temas que se tornariam importantes para suas pesquisas posteriores: a periodização do Estado capitalista e a distinção entre regimes normais e excepcionais. Poder político e classes sociais focalizou o tipo capitalista de Estado em sua forma genérica normal (democracia burguesa liberal) e ofereceu comentários limitados sobre o absolutismo, o bonapartismo, o bismarckismo, o fascismo e o totalitarismo. Pesquisas posteriores investigaram formas excepcionais do Estado capitalista, particularmente o fascismo e as ditaduras militares, e o Estado intervencionista. O Estado, o poder, o socialismo combinou essas preocupações na proposição de que o tipo capitalista de Estado é agora "permanente e crucialmente caracterizado por uma agudização peculiar dos elementos genéricos da crise política e da crise do Estado", mais que se preocupar em mostrar sinais intermitentes de crises conjunturais, de curto prazo. A base dessa proposição foi elaborada em um ensaio sobre "A crise do Estado" (POULANTZAS, 1976b), que rejeitou as perspec- 
tivas alternativas de que as crises no capitalismo são acidentais e disfuncionais e que elas são permanentes e catastróficas. O próprio Poulantzas argumentou que, enquanto os elementos genéricos de crises são constantemente reproduzidos nas sociedades capitalistas, as crises somente surgem quando esses elementos condensam-se em uma conjuntura distinta e desenvolvem-se de acordo com ritmos e flutuações específicos (idem, p. 22, 28). As gêneses e os ritmos de crises particulares do Estado e no campo político devem portanto ser estudados caso a caso mais que atribuídos a crises institucionais ou políticas permanentes. Elas devem relacionar-se primeiramente ao campo das relações políticas de classe e apenas secundariamente a instituições políticas específicas (POULANTZAS, 1974, p. 63; 1976b, p. 23, 28).

Apenas um tipo de crise política produz uma forma excepcional de Estado, qual seja, a crise de hegemonia no interior do bloco no poder. Isso ocorre quando nenhuma classe ou fração de classe consegue impor sua "liderança" sobre os outros membros do bloco no poder, seja por meio de suas próprias organizações políticas, seja por meio do Estado “democrático-parlamentar”. Isso se relaciona tipicamente a uma crise geral de hegemonia sobre o todo da sociedade (POULANTZAS, 1974, p. 72, 100-101, 124-125). Tais crises refletem-se na cena política e no sistema estatal. Os seus sintomas incluem: uma crise da representação partidária, isto é, uma ruptura entre diferentes classes ou frações de classe e seus partidos (idem, p. 73, 102, 126); tentativas de várias forças sociais para contornar os partidos políticos e influenciar diretamente o Estado; esforços de diferentes aparatos do Estado para impor a ordem política independentemente de decisões vindas dos canais formais do poder (idem, p. 74, 102-103; 1976b, p. 28). Tais fenômenos podem minar a unidade institucional e de classe do Estado, mesmo onde ele continua a funcionar, e provocar uma ruptura entre altos escalões no sistema estatal e seus níveis inferiores (POULANTZAS, 1974, p. 334). O Estado também pode perder o seu monopólio da violência (idem, p. 335).

Os resultados das crises políticas sempre dependem da natureza e das modalidades das estratégias e das lutas de classes. Por exemplo, o fascismo surgiu porque uma crise política coincidiu com um passo ofensivo da burguesia e um passo defensivo da classe trabalhadora (idem, p. 78-82, 107-108, 130-131, 139-147). Assim, as lutas de classes podem não apenas contribuir para a gênese das crises políticas mas também podem determinar se elas são resolvidas pela restauração da democracia ou recorrendo a um Estado de exceção. As crises econômicas não causam diretamente as crises política e do Estado, embora elas moldem, sim, a conjuntura em que tais crises surgem, especialmente no estágio do capitalismo monopolista, com seus vínculos cerrados entre os poderes político e econômico (idem, p. 53; 1976b, p. 25, 34). Quando as crises afetam todas as relações sociais mais que um campo de relações particulares, elas tornam-se crises "orgânicas" ou "estruturais” (POULANTZAS, 1976b, p. 26).

A análise de Poulantzas do Estado de exceção deriva de sua perspectiva de que os traços definitivos da forma normal do tipo capitalista de Estado são as instituições democráticas e a liderança hegemônica de classe. Os estados normais correspondem a conjunturas em que a hegemonia burguesa é estável e segura; estados de exceção são respostas a crises de hegemonia (POULANTZAS, 1973, p. 293; 1974, p. 11, 5759, 72, 298, 313; 1976a, p. 92-93). Assim, enquanto o consentimento predomina sobre a violência constitucionalizada em estados normais, os estados de exceção intensificam a repressão física e conduz a uma "guerra aberta" contra as classes dominadas (POULANTZAS, 1973, p. 226; 1974, p. 152, 316-318, 330; 1976a, p. 9, 92, 129). Esse contraste básico é refletido em quatro conjuntos de diferenças institucionais e operacionais entre as duas formas de Estado:

1. enquanto o Estado normal tem instituições democráticas representativas com sufrágio universal e partidos políticos competitivos, os estados de exceção suspendem o princípio eleitoral (à parte plebiscitos e/ou referendos controlados cerradamente pelo alto) e acabam com o sistema partidário pluralista (POULANTZAS, 1973, p. 123, 230; 1974, p. 324-327; 1976a, p. 42, 91, 114);

2. a transferência do poder em estados normais segue as regras legais e constitucionais e ocorre em vias estáveis e previsíveis. Os estados de exceção suspendem o império da lei, entretanto, para facilitar as mudanças constitucionais e administrativas supostamente requeridas para ajudar a so- 
lucionar a crise de hegemonia (POULANTZAS, 1973, p. 226-227, 311; 1974, p. 320-324; 1978a, p. 87-92);

3. os aparatos ideológicos do Estado em estados normais tipicamente possuem status legal "privado" e desfrutam de significativa autonomia do controle governamental oficial. Em contraste, os aparatos ideológicos em estados de exceção são geralmente subordinados ao aparato repressivo do Estado e são faltos de independência real. Essa subordinação serve para legitimar o recurso maior à coerção e auxilia a ultrapassar a crise ideológica que acompanha uma crise de hegemonia (POULANTZAS, 1974, p. 314-318; 1976a, p. 113-114);

4. a separação formal de poderes no aparato repressivo do Estado também é reduzida por meio da infiltração de ramos subordinados e dos centros de poder pelo ramo dominante e/ou por meio da expansão de redes de poder e correias de transmissão paralelas que se cruzam e vinculam diferentes ramos e centros. Isso produz grande centralização do poder político e multiplica seus pontos de aplicação no Estado. Tudo isso serve para reorganizar a hegemonia, para neutralizar divisões internas e para provocar curto-circuitos em resistências internas, além de assegurar a flexibilidade em face da inércia burocrática (POULANTZAS, 1974, p. 315316, 327-330; 1976a, p. 50, 92, 100-101; 1978a, p. 87-92).

Poulantzas argumentou que as instituições democráticas representativas facilitam a circulação e a reorganização orgânicas da hegemonia porque oferecem um espaço para os conflitos abertos de classes e de frações de classe. As instituições democráticas, dessa forma, inibem maiores rupturas ou quebras na coesão social e, a fortiori, no sistema de dominação política de classe. Entretanto, se as crises política e ideológica não podem ser resolvidas por meio da atuação normal e democrática de forças de classes, as instituições democráticas devem ser suspensas ou eliminadas e as crises resolvidas por meio de uma "guerra de manobras" aberta que ignora as delicadezas constitucionais. Mas o próprio ato de abolir as instituições democráticas tende a congelar o equilíbrio de forças prevalecente quando o Estado de exceção é estabilizado. Isso torna mais difícil resolver novas crises e contradições por meio da rotina e de ajustes políticos graduais e estabelecer um novo equilíbrio de compromisso. Assim, Poulantzas concluiu que a suposta força do Estado de exceção na verdade esconde sua real fragilidade. Isso torna os estados de exceção vulneráveis ao colapso súbito quanto as contradições e as pressões acumulam-se. Por outro lado, a aparente fraqueza dos estados democráticos curva-se sob pressão e, portanto, fornece meios mais flexíveis para organizar a dominação política de classe (POULANTZAS, 1976a, p. 30, 38, 48-50, 90-93, 106, 124).

Se esses traços tipificam os regimes mais flexíveis, regimes "frágeis" revelam as características opostas. Eles carecem de qualquer aparato político-ideológico especializado para canalizar e controlar o apoio das massas e, assim, são isolados das massas. Eles exibem uma rígida partilha do poder do Estado entre vários e distintos "clãs" políticos entrincheirados em cada aparato. E falta-lhes uma ideologia que possa forjar a necessária unidade estatal e estabelecer uma efetiva coesão nacional-popular. Isso produz uma confusão de políticas inconsistentes em relação às massas quando o regime de exceção procura neutralizar sua oposição. Isso também leva a compromissos puramente mecânicos, alianças táticas e acertos de contas entre interesses "econômicocorporativos" entre as classes e as frações de classe dominantes. Por outro lado, intensifica as contradições internas do aparato de Estado e reduz sua flexibilidade face às crises econômicas e/ou políticas (idem, p. 49-50, 55-57, 79-80, 83-84, 91-94, 112-113, 120-121, 124-126).

Poulantzas claramente viu importantes diferenças entre as formas excepcionais do Estado e estava particularmente impressionado pela flexibilidade e pela capacidade de manobra do fascismo. Em contraste, a ditadura militar é o tipo menos flexível e o bonapartismo está localizado a meiocaminho entre esses extremos (JESSOP, 1985). Mas ele também insistiu que nenhum regime de exceção pode assegurar o tipo de regulação flexível e orgânica das forças sociais e a suave circulação de hegemonia que ocorre sob as democracias burguesas (POULANTZAS, 1976a, p. 124). Dessa forma, assim como o movimento de um Estado normal para um de exceção envolve crises e rupturas políticas, mais que a tomada de uma trilha contínua e linear, a transição de uma forma 
de exceção para uma normal também envolverá uma série de rachas e crises, mais que um simples processo de auto-transformação. Isso coloca um prêmio sobre a luta política de classes para adquirir a hegemonia no processo de democratização. De fato, Poulantzas insistiu que o caráter de classe do Estado normal variará significativamente com o resultado dessa luta (idem, p. 9097, 124 et passim).

\section{ESTATISMO AUTORITÁRIO}

Essas idéias foram desenvolvidas na perspectiva de Poulantzas sobre a nova forma "normal" do tipo capitalista de Estado, isto é, o "estatismo autoritário”. Sua tendência básica de desenvolvimento é descrita como "o controle intensificado do Estado sobre cada esfera da vida sócio-econômica combinado com o declínio radical das instituições da democracia política e com a restrição draconiana e multiforme das assim chamadas liberdades 'formais'” (POULANTZAS, 1978a, p. 203-204). Mais especificamente, os principais elementos do "estatismo autoritário" e suas implicações para a democracia representativa incluem: em primeiro lugar, uma transferência do poder do ramo Legislativo para o ramo Executivo e a concentração de poder no segundo; depois, uma fusão acelerada dos poderes Legislativo, Executivo e Judiciário, acompanhada de um declínio do império da lei; em terceiro lugar, o declínio funcional dos partidos políticos como canais principais para o diálogo político com a administração e como as maiores forças na organização da hegemonia; finalmente, o crescimento das redes paralelas de poder atravessando a organização formal do Estado e mantendo uma decisiva parcela de suas várias atividades (POULANTZAS, 1973, p. 303307, 310-315; 1975, p. 173; 1976b, p. 55-57; 1978a, p. 217-231; 1979, p. 132).

Essas mudanças são características permanentes e estruturais do Estado moderno. Elas correspondem a uma agudização peculiar dos elementos genéricos da crise política e estatal acompanhando a crise econômica de longo prazo que supostamente cerca toda a fase atual do modo capitalista de produção. Entre as mais importantes tendências da crise nessa fase estão: a politização da resistência da classe trabalhadora contra os esforços do capital para resolver a crise econômica; a politização da nova pequena burguesia devido ao aprofundamento da divisão social do trabalho nos níveis do próprio trabalho in- telectual; a decomposição da tradicional aliança entre a burguesia e a antiga e a nova pequenas burguesias; a crise ideológica que acompanha o crescimento dos novos movimentos sociais em frontes anteriormente "secundários"; a agudização das contradições no bloco do poder devido à divisão tendencial do trabalho entre o factótum [comprador $^{6}$ ] e as frações interiores do capital (POULANTZAS, 1978a, p. 210-214, 219, 221).

Além disso, se o Estado desobriga-se ou intervém para moderar uma determinada tendênciacrise em uma área, ele agrava outras tendênciascrise em outras áreas. Assim, a habilidade do Estado posterior à II Guerra Mundial para moderar os aspectos "mais selvagens" das crises capitalistas no capitalismo avançado (como foi evidente nos anos 1930) requer dele que assuma responsabilidade direta pelos efeitos purgativos da crise. Isso pode ameaçar suas legitimidade e estabilidade e ocorre porque se tornou muito mais árduo para a fração dominante sacrificar seus interesses econômico-corporativos de curto prazo para promover sua hegemonia política de longo prazo. Ainda assim, o fracasso em atuar contra as tendências-crise econômicas arruinará a acumulação de capital. Da mesma forma, o crescente envolvimento do Estado em áreas até então marginais da vida social politiza as massas populares - especialmente como os compromissos de políticas sociais do período posterior à II Guerra Mundial excluem cortes de gastos, austeridade, por um lado, e, por outro lado, a remercantilização [recommodification] e a resultante crise de legitimação conduz as massas a confrontar diretamente o Estado e a ameaçar sua estabilidade. Mas qualquer falha em intervir nessas áreas minará a reprodução social da força de trabalho. $\mathrm{O}$ crescente papel do Estado para promover a internacionalização do capital também acarreta problemas para a unidade nacional. Isso é especialmente claro em seu impacto nas regiões menos desenvolvidas e nas minorias nacionais (idem, $\mathrm{p}$. 141-142, 153-154, 210-214, 219, 221, 245-246).

\footnotetext{
6 Embora aqui e ali o autor utilize expressões menos comuns na língua inglesa, nesse caso ele utilizou "comprador”, que se referia, durante a dominação inglesa direta na China, no século XIX e início do século XX, aos encarregados nativos dos negócios estrangeiros. A tradução por “factótum”, assim, é bastante adequada e, na verdade, literal (N. T.).
} 
Poulantzas previamente argumentou que os regimes de exceção são sempre temporários e ocorrem em resposta a conjunturas específicas. Dessa forma, como essas tendências-crise são traços permanentes do capitalismo contemporâneo, o estatismo autoritário deve ser visto como normal. Afinal, traços "excepcionais” significativos co-existem com e modificam os traços "normais” do tipo capitalista de Estado, pois eles são orquestrados em uma estrutura permanente que funciona paralelamente ao sistema estatal oficial. Isso envolve uma simbiose constante e uma intersecção funcional das estruturas normais e excepcionais sob o controle das cúpulas que comandam o aparato estatal e o partido dominante (idem, p. 208, 210, 245; cf. POULANTZAS, 1979, p. 132). O poder real está concentrado e centralizado nas cúpulas do sistema governamental e administrativo, que se fecha para o papel representativo dos partidos e dos parlamentos. Os últimos são agora simples "câmaras de registro" eleitorais com poderes bastante limitados e é a administração do Estado, guiada pelo poder Executivo político, que se tornou o principal lócus para o desenvolvimento da política estatal. Isso politiza maciçamente a administração e põe-na em risco de fragmentação atrás de uma fachada formal de hierarquia e unidade burocráticas (POULANTZAS, 1978a, p. 236). De fato, a política é cada vez mais focalizada na equipe de governo [staff office] de um Presidente ou de um Primeiro-Ministro. Mantendo-se no ápice das estruturas administrativas, essa equipe aparece como um sistema presidencial-chanceleresco ${ }^{7}$ puramente personalístico. Mas ela de fato condensa muitas pressões contraditórias e trabalha para re-equilibrar as forças conflitivas e os interesses populares que ainda emergem na forma de contradições dentro da administração (idem, p. 221-224, 226-229, 233, 236-238; cf. POULANTZAS, 1973, p. 311-314).

Poulantzas relacionou esse "irresistível crescimento da administração do Estado” principalmente ao crescente papel econômico do Estado conforme modificado pela situação política. Por

\footnotetext{
7 No original: “presidential-prime-ministerial”. Para evitar o desagradável "presidencial-primeiro-ministerial”, preferimos trocar a expressão "Primeiro-Ministro" pelo seu equivalente "Chanceler" e daí utilizar o respectivo adjetivo (N. T.).
}

“intervenção do Estado” ele queria dizer que a lei não pode mais ser confinada às normas gerais, formais e universais cuja representação é preservar o parlamento como a incorporação da vontade geral do povo-nação. O império da lei é enfraquecido porque as normas legais são crescentemente modificadas e elaboradas pela administração para lidar com conjunturas, situações e interesses particulares e porque a formulação inicial das leis é agora também largamente empreendida pela administração, mais que pelo parlamento (POULANTZAS, 1978a, p. 218-219; cf. SCHEUERMAN, 2005). Essa mudança é o produto da permanente instabilidade do monopólio da hegemonia no interior do bloco no poder e sobre o povo, bem como dos cambiantes imperativos econômicos. De fato, o declínio do império da lei também afeta a esfera política. Um sinal disso é a crescente ênfase no policiamento preventivo dos potencialmente desleais e desviantes, mais que na punição judicial das ofensas à lei claramente definidas (POULANTZAS, 1978a, p. 219-220). Mais geralmente, a crise do monopólio da hegemonia significa que a administração do Estado torna-se o lócus central no qual o equilíbrio instável do compromisso entre o bloco no poder e as massas populares é elaborado dentro do próprio bloco no poder. Isso também transforma os partidos do poder (ou os "partidos naturais do governo", em contraste com aqueles partidos destinados a um permanente papel de oposição) em um único (ou duopolístico) partido autoritário de massa cuja tarefa é mais mobilizar o apoio das massas para as políticas estatais de uma forma plebiscitária que diretamente articular e representar os interesses e as demandas populares no Estado. Isso também se relaciona com uma crescente e densa rede de vínculos transversais entre os grandes negócios e os aparatos administrativos centrais do Estado (especialmente os aparatos econômicos) e com um aumento geral no centralismo político e administrativo. Um último aspecto aqui é o fortalecido personalismo do poder no topo do poder Executivo. Isso não envolve um genuíno ditador bonapartista, que concentra os poderes despóticos em suas mãos, mas, por outro lado, envolve a busca de uma figura de proa carismática que possa conferir um sentido de direção estratégica às complexidades da política tanto para as classes dominantes quanto, de uma forma mais plebiscitária, para as massas populares (cf. GRANDE, 2000). Não obstante, Poulantzas 
conclui que tal centralização do poder administrativo às expensas do parlamento, dos partidos populares e das liberdades democráticas não significa que o Estado foi enormemente fortalecido. Ao contrário, ele enfatiza a relativa fraqueza do Estado autoritário face à crescente incompressibilidade das contradições econômicas das tendências-crise e face às novas formas de luta popular.

Também há mudanças entre os partidos no poder "que buscam participar, e de fato participam, do governo de acordo com um padrão de alternância regular que é fixado e antecipado organicamente pelas instituições estatais existentes como um todo (e não apenas pelas regras constitucionais)" (POULANTZAS, 1978a, p. 220). Seus vínculos de representação no bloco no poder tornam-se mais frouxos porque é mais árduo para o capital monopolista organizar sua hegemonia por meio dos partidos parlamentares e, portanto, concentra sua pressão sobre a administração (POULANTZAS, 1974, p. 171; 1973, p. 313, 313n14, 320; 1978a, p. 221-223). Assim, os partidos não cumprem mais suas funções tradicionais de formulação de políticas (por meio de compromissos e alianças ao redor de um programa partidário comum) e de legitimação política (por meio da competição eleitoral para um mandato nacional-popular). Eles agora são pouco mais que correias de transmissão para as decisões oficiais e diferem meramente nos aspectos da política oficial que escolhem popularizar (POULANTZAS, 1978a, p. 229-230, 237). Por outro lado, a legitimação política é redirecionada por meio de canais baseados em técnicas plebiscitárias e manipulatórias que são dominadas pelo poder Executivo e canalizadas pelos meios de comunicação de massa (idem, p. 229).

Não obstante, as atividades da administração estatal continuamente vão de encontro aos limites inerentes às suas próprias estrutura e operação políticas. Esses limites são particularmente claros nas divisões internas entre os diferentes grupelhos, clãs e facções administrativos e na reprodução dentro do sistema estatal de conflitos e contradições de classe. Assim, devemos perguntar como a administração ultrapassa essas tensões de modo a atuar efetivamente em benefício do capital monopolista. Estados de exceção obtêm-no por meio de um aparato político (como o partido fascista, as Forças Armadas ou a polícia política), que é distinto da administração. Na forma teoricamente normal da democracia representativa, isso é atingido por meio do funcionamento orgânico de um sistema partidário pluralista localizado a certa distância do aparato administrativo central (idem, p. 231, 232-233; cf. POULANTZAS, 1974, p. 316-317, 332, 340-341, 353; 1973, p. 318-320, 335-337, 345-346, 348, 353-355; 1976a, p. 33, 104-107). Mas como isso pode realizar-se no estatismo autoritário?

Poulantzas sugeriu que o partido de massas dominante funciona como uma rede paralela e atua como um comissário político no coração da administração, desenvolvendo uma comunidade material e ideológica de interesses com funcionários civis-chave. Esse mesmo partido também deve transmitir a ideologia do Estado às massas populares e reforçar a legitimação plebiscitária do estatismo autoritário (POULANTZAS, 1978a, p. 236-237). Daí que o partido de massas dominante na verdade funciona como o partido de Estado dominante, pois ele representa o Estado para as massas, mais que as massas para o Estado. Um tal partido de massas altamente unificado e estruturado desenvolve-se muito provavelmente durante um longo período sem alternância entre os partidos governantes. Mas funções similares podem ser desenvolvidas por um único "centro" intrapartidário que domina os partidos alternativos do poder (idem, p. 232, 235-236).

O surgimento irresistível da administração do Estado no capitalismo metropolitano não pode evitar uma agudização posterior dos elementos genéricos da crise política e do Estado. Os exemplos incluem: a) a politização da burocracia, especialmente entre os seus níveis inferiores, em oposição ao "partido de Estado" dominante; b) as maiores dificuldades enfrentadas pela administração que por um sistema político partidário flexível para organizar a hegemonia e gerenciar o instável compromisso do equilíbrio de classes; c) o crescimento e o impacto das lutas de massas precipitadas por novas formas de intervenção estatal com efeitos potencialmente maiores de deslocamento dentro do próprio Estado (idem, p. 240247). Dessa forma, o surgimento do "estatismo autoritário" envolve um paradoxo. Enquanto ele claramente fortalece o poder do Estado às expensas da democracia representativa liberal, ele também enfraquece suas capacidades para assegurar a hegemonia burguesa (idem, p. 241, 263-265). 


\section{O ESTATISMO AUTORITÁRIO HOJE}

A análise de Poulantzas sobre o estatismo autoritário foi notavelmente presciente quando escrita pela primeira vez há cerca de 25 anos. As várias tendências que ela identificou em $O$ Estado, o poder, o socialismo e que subsumiu na rubrica geral de "estatismo autoritário" têm-se tornado, desde então, cada vez mais claras como respostas para a crescente crise política no bloco do poder, para a crise de representação no sistema político, para as crises de legitimação e do Estado associadas às falhas gêmeas do Estado intervencionista posterior à II Guerra Mundial e à guinada neoliberal e o crescente desafio à primazia do Estado territorial nacional pela globalização. Deveríamos notar particularmente o declínio continuado do parlamento e do império da lei; a crescente autonomia do poder Executivo; a importância aumentada dos poderes presidenciais ou chancelerescos; a consolidação dos partidos autoritários e plebiscitários que largamente representam o Estado para as massas populares e - algo negligenciado por Poulantzas - a "midiatização" da política, com os meios de comunicação de massa desempenhando um crescente papel na formatação dos imaginários, programas e debates políticos. Uma grande ênfase em temas de segurança nacional e policiamento preventivo associada à assim chamada guerra contra o terror em casa e no exterior também reforçam o ataque aos direitos humanos e às liberdades civis. O Novo Trabalhismo $^{8}$ é uma ilustração particularmente constrangedora dessas tendências, mas os mesmos traços também são completamente evidentes nos Estados Unidos, na Itália, na Espanha, na França, na Alemanha e em várias outras sociedades metropolitanas. Isso apresenta interessantes questões não apenas a respeito de como e por que Poulantzas poderia predizer essas tendências, mas também se e, em caso afirmativo, por que ele deixou de lado outras características igualmente importantes da atual forma normal do Estado capitalista.

8 No original, “New Labour”. O autor faz referência às práticas adotadas pelo Partido Trabalhista britânico (Labour Party) de meados da década de 1990 a meados da década de 2000, em que, sob a liderança de Tony Blair, fizeram-se numerosas concessões ao chamado neoliberalismo, a fim de garantir a competitividade econômica internacional da Inglaterra e também para vencer as diversas eleições parlamentares. Além disso, a partir de 2001, a Inglaterra tornouse aliada dos Estados Unidos de George W. Bush na "guerra contra o terror" (N. T.)
Seu sucesso pode ser explicado em termos de seu compromisso de combinar as análises teóricas e históricas, mais que de empenhar-se em um rude Staatsableitere $i^{9}$ ou de reduzir cada forma do Estado capitalista a uma simples ditadura da burguesia ${ }^{10}$. Assim, teoricamente, Poulantzas argumentou que uma periodização adequada do tipo capitalista de Estado deveria considerar as formas cambiantes da articulação das suas funções econômica, política e ideológica, vinculada aos diferentes estágios do capitalismo. Sua obra inicial já discutia a correlação entre o capitalismo competitivo e o Estado liberal, o capitalismo monopolista e o Estado intervencionista e o capitalismo monopolista e o "Estado forte" (cf. POULANTZAS, 1974; 1973; 1975). As pesquisas presentes em As classes sociais no capitalismo de hoje e, especialmente, em $O$ Estado, o poder, o socialismo forneceram análises significativas sobre as mudanças nas relações sociais de produção; sobre a relação entre as condições econômicas e extra-econômicas de valorização; sobre as formas dominantes de competição e sobre a cadeia imperialista. Combinadas com sua análise mais sofisticada presente em $O$ Estado, o poder, o socialismo sobre os momentos econômico, político e ideológico das relações sociais de produção e as mutáveis matrizes espaço-temporais da acumulação de capital, as análises precedentes permitiram-lhe teorizar a "forma transformada" das funções econômicas do "Estado forte” em sua última fase (POULANTZAS, 1978a, parte III, cap. 1-2). Essa análise também está explicitamente em dívida tanto com as pesquisas empíricas quanto com as teóricas dos analistas franceses contemporâneos do capitalismo monopolista de Estado, especialmente no concernente à lei da sobre-acumulação-desvalorização e às demandas mutáveis da reprodução da força de trabalho ${ }^{11}$. Ele foi além dessas pesquisas, entretanto, ao enfatizar a sobredeterminação política das respostas do Es-

9 “Derivacionismo do Estado”, em alemão no original. Referência às teorias de Joachim Hirsch, Elmar Altvater e outros que procuravam derivar a forma-Estado da natureza das relações de exploração do trabalho pelo capital (nota do revisor da tradução).

10 Sobre a importância dessa abordagem, cf. a seção 5 da “Introdução” de Poder político e classes sociais.

11 Para apreciações críticas dessas pesquisas, cf. Fairley (1990) e Jessop e Sum (2006). 
tado forte para a crise econômica, especialmente em um período que também foi marcado pela crise política e do Estado.

Sua análise do distinto caráter político do estatismo autoritário também adiantou explicitamente pesquisas contemporâneas sobre o Estado nas formações sociais capitalistas metropolitanas, bem como uma cuidadosa generalização teórica a partir do caso do fascismo como a mais flexível forma de regime de exceção, atualizada do período entre-guerras para o presente estágio do capitalismo e adequadamente modificada para permitir a "normalidade" do estatismo autoritário. Dado esse ponto de partida teórico e suas reflexões mais gerais sobre a particularidade das crises política e do Estado no capitalismo contemporâneo, Poulantzas também parece ter extrapolado características-chave do estatismo autoritário da experiência francesa, com sua forte tradição estatista e a história posterior à II Guerra Mundial do gaullismo ${ }^{12}$. Ele provavelmente também foi influenciado pelo caráter do CDU-Staat ${ }^{13}$ na Alemanha e sua subseqüente transformação em um Sicherheitsstaat ${ }^{14}$. O que distingue as análises de Poulantzas das críticas contemporâneas libertárias, liberais e esquerdistas do autoritarismo insidioso é sua habilidade para localizar essas tendências em uma análise forma-analítica, estratégicorelacional do tipo capitalista de Estado, combinado com uma interpretação distinta do imperialismo contemporâneo e com uma análise neogramsciana da crise política do bloco no po-

12 Enquanto quase todas as pesquisas empíricas citadas nas seções relevantes de $O$ Estado, o poder, o socialismo referem-se à experiência francesa contemporânea, Poulantzas também estava bastante ciente de obras similares sobre o Estado alemão.

13 Literalmente "Estado-CDU”, em alemão no original. Em 1957 a CDU (Christlich-Demokratische Union Deutschlands - União Democrático-Cristã da Alemanha) obteve pela primeira vez na história da Alemanha a maioria absoluta das cadeiras no Parlamento, dominando amplamente a vida política nacional. Esse domínio ficou caracrterizado com a expressão “CDU-Staat” (N. R. T.).

14 “Estado de Segurança”, em alemão no original. O Estado de Segurança designa um Estado burocratizado voltado para o controle e a disciplina da classe trabalhadora. A expressão é utilizada por Joachim Hirsch no livro Der Sicherheitsstaat: Das "Modell Deutschland”, seine Krise und die neuen sozialen Bewegungen (Frankfurt am Main: Europäische Verlagsanstalt, 1980) (N. R. T.). der e de sua hegemonia e, ao assim fazer, mostrando que a intensificação das características genéricas dos regimes de exceção envolvem tanto um fortalecimento quanto um enfraquecimento do tipo capitalista de Estado. Isso ilustra bem o poder heurístico e explanatório de sua tese-chave que é o Estado como uma relação social.

Dito isso, a interpretação de Poulantzas do estatismo autoritário é problemática. Afinal, se ela adequadamente descreve algumas importantes tendências autoritárias na corrente forma do tipo capitalista de Estado, isso pode ser atribuído à exitosa extrapolação de tendências amplamente notáveis da assunção da contínua instabilidade da hegemonia do bloco no poder. A extrapolação provou-se menos frutífera, entretanto, em outros aspectos (ver abaixo). Há também alguns problemas mais básicos com o conceito de estatismo autoritário como desenvolvido por Poulantzas. Em primeiro lugar, relativamente ao peso conferido a ela na explicação da gênese do estatismo autoritário, Poulantzas dificilmente discute a natureza da hegemonia e sua crise no capitalismo contemporâneo. Em segundo lugar, e relacionado à questão anterior, ele não mostrou como os traços excepcionais do estatismo autoritário articulam-se sob a dominação dos elementos normais - o que é crucial para sua afirmação de que essa nova forma de Estado capitalista é um Estado democrático normal. Em terceiro lugar, enquanto seus princípios metodológicos e teóricos anteriores requereram dele que mostrasse como o surgimento do “estatismo autoritário" enseja uma quebra ou uma ruptura no processo político (desde que envolve uma transição para uma nova forma de Estado), ele admitiu que isso resulta da gradual acentuação de tendências coetâneas do capitalismo monopolista e assim típicas dos estados intervencionistas. É com essa base que ele pôde exitosamente extrapolar algumas dessas tendências no período mais recente do capitalismo monopolista de Estado e fracassou em predizer a dominação da guinada neoliberal na transição para um regime de acumulação globalizante e pósfordista que caracterizaria esse último período. Em particular, Poulantzas parece não ter antecipado o sucesso da ofensiva do capital monopolista e o enfraquecimento do trabalho organizado em resposta à crise do fordismo atlântico e de seus estados nacionais keynesianos de bem-estar. Uma completa análise estratégico-relacional teria sido de grande ajuda aqui. Em quarto lugar, a despeito 
de seu reconhecimento em $O$ Estado, o poder, o socialismo de que as matrizes espaço-temporais da acumulação de capital foram radicalmente reorganizadas, sua análise do estatismo autoritário ainda estava pesadamente marcada pela assunção de que o Estado nacional permaneceria a escala dominante em que a dominação política de classe poderia ser organizada. Em suma, mesmo que aceitemos a interpretação basicamente descritiva de Poulantzas sobre o "estatismo autoritário" como uma forma normal do Estado capitalista, ele é menos convincente ao explicar seu surgimento e seu futuro desenvolvimento.

Além disso, a despeito de sua surpreendente acuidade teórica e sua impressionante presciência em alguns assuntos, ele deixou outros importantes desenvolvimentos e tendências do capitalismo contemporâneo. Em primeiro lugar, ao focalizar as formas mutáveis da intervenção econômica estatal e ao iluminar seu papel na redefinição das fronteiras entre o econômico e o extra-econômico, ele ignorou as mudanças na dinâmica global da acumulação de capital que estão associadas à transição do fordismo atlântico para uma economia globalizante baseada no conhecimento. Em segundo lugar, ao focalizar no papel dos estados nacionais no imperialismo contemporâneo, ele falhou em notar o quanto a interpenetração multidimensional dos espaços econômicos que identificou em As classes sociais no capitalismo de hoje também implicou um redimensionamento dos aparatos e do poder de Estado. Embora tenha corretamente rejeitado o mito do Estado mundial ou de um único super-Estado, ele não previu a extensão em que os aparatos e os poderes do Estado foram redimensionados para cima, para baixo e para os lados, em um esforço para lidar com uma economia mundial crescentemente complexa. Esse redimensionamento dos poderes particulares do Estado não diminuem a insistência de Poulantzas sobre a contínua centralidade do Estado nacional para assegurar as condições para a coesão social mas que, por outro lado, enfraquece suas capacidades para realizar sua função geral crucial. Em terceiro lugar, embora ele tenha reconhecido o papel vital das redes nas operações do Estado (i.e., redes de poder paralelo dentro do Estado para assegurar uma medida de unidade do aparato; redes de poder de negócios e administrativo nos cimos do aparato econômico do Estado para facilitar a elaboração de estratégias econômicas em favor do capital monopolista; redes entre os partidos do poder), ele não percebeu para quão longe isso deslocaria o exercício do poder do Estado, do planejamento de cima para baixo e do jugo hierárquico em direção à descentralização guiada pelo contexto [context-steering] e a outras formas de governança à sombra da hierarquia.

Não obstante essas críticas de conclusão, Poulantzas permanece uma figura crucial no desenvolvimento de uma teoria materialista do Estado. Sua percepção de que o Estado é uma relação social não apenas revigorou sua interpretação mais abstrato-simples forma-analítica do tipo capitalista de Estado como também forneceu uma poderosa abordagem para lidar com as características concreto-complexas dos estados de fato existentes nas sociedades capitalistas. Não se pode dizer que ele completou a teoria marxista do Estado capitalista - quando menos porque teoria, mesmo que fosse possível, não poderia ser completada, pois a deslocada e descontínua reprodução expandida da relação do capital e a luta contra tal reprodução continua em novas formas. Mas certamente se pode reconhecê-lo por seu papel em fornecer aos teóricos e militantes que lhe sucederam uma estrutura teórica e conceitual rica e complexa com que analisar o processo contraditório e conflituoso da reprodução expandida do ponto de vista da contribuição estratégico-relacional do Estado (e do sistema interestatal) para organizar um bloco no poder e para desorganizar as classes subalternas, em diferentes períodos, estágios e conjunturas. Em suma, os textos de Poulantzas podem ser considerados como clássicos modernos no sentido de que apresentam importantes questões e fornecem respostas que, mesmo que não sejam mais consideradas totalmente adequadas, ainda assim nos orientam para a direção correta. O reconhecimento contínuo como um texto "clássico" não é garantido. De fato, "para que um texto adquira a distinção de 'clássico', ele tipicamente deve superar uma variedade de barreiras culturais; ao passo que, para sobreviver como um [clássico], ele deve submeter-se ao contínuo engajamento crítico; seus conceitos [devem ser] reformulados para encontrar novos problemas e avaliações” (BAEHR \& O’BRIEN, 1994, p. 127128). A obra de Poulantzas tem disparado um renovado engajamento crítico - como o presente artigo indica - e seus conceitos certamente podem ser redispostos e reformulados para permitir-nos enfrentar novos problemas e avaliações. 
Bob Jessop (b.jessop@lancaster.ac.uk) é Doutor em Economia e Política pela Universidade de Cambridge e Distinguished Professor of Sociology na Universidade de Lancaster, ambas na Inglaterra.

\section{REFERÊNCIAS BIBLIOGRÁFICAS}

BAEHR, P. \& O'BRIEN, M. 1994. Founders, Classics and the Concept of a Canon. Current Sociology, London, v. 42, n. 1, p. 1-151, Mar.

FAIRLEY, J. 1980. French Theories of State Monopoly Capitalism. Science \& Society, New York, v. 44, n. 3, p. 305-325, Fall.

GRAMSCI, A. 1971. Selections from the Prison Notebooks. London : Lawrence \& Wishart.

GRANDE, E. 2000. Charisma und Komplexität. Verhandlungsdemokratie, Medien-demokratie und der Funktionswandel politischer Eliten. Leviathan, Wiesbaden, v. 28, n. 1, p. 122-141.

HALL, S.; CRITCHER, C.; JEFFERSON, T.; CLARKE, J. \& ROBERTS, B. 1978. Policing the Crisis : "Mugging”, the State, and Law and Order. Basingstoke : Macmillan.

JESSOP, B. 1982. The Capitalist State. Oxford : M. Robertson.

1985. Nicos Poulantzas : Marxist Theory and Political Strategy. Basingstoke : Macmillan.

1990. State Theory. Cambridge : Polity.

1999. Globalisierung und Nationalstaat. Imperialismus und Staat bei Nicos Poulantzas - 20 Jahre später. Prokla, n. 116, p. 469-495.

2002. The Future of the Capitalist State. Cambridge : Polity.

2006a. Kapitalistischer Staatstyp und autoritärer Etatismus. Poulantzas's Staatstheorie als moderner Klassik. In : BRETTHAUER, L.; GALLAS, A.; KANANKULAM, J. \& STÜTZLE, I. (eds.). Poulantzas Lesen : Zur Aktualität marxistischer Staatstheorie. Hamburg : VSA. 2006b. Poulantzas's State, Power, Socialism as a Modern Classic. Disponível em : http://mercury.soas.ac.uk/hm/pdf/2006 confpapers/papers/Jessop.pdf. Acesso em : 4.mar.2009.

JESSOP, B. \& SUM, N. 2006. Beyond the Regulation Approach : Putting Capitalist Economies in their Place. Cheltenham : E. Elgar.

MARX, K. 1967. Capital. V. I. London : Lawrence \& Wishart.

POULANTZAS, N. 1973. Political Power and Social Classes. London : New Left.

1974. Fascism and Dictatorship. London : New Left.

1975. Classes in Contemporary Capitalism. London : Verso.

1976a. Crisis of the Dictatorships : Portugal, Greece, Spain. London : Verso.

1976b. Les transformations actuelles de l'État, la crise politique et la crise de l'État. In : _ (ed.). La crise de l'État. Paris : PUF.

1978a. State, Power, Socialism. London : New Left.

1978b. Les théoriciens doivent retourner sur terre. Les nouvelles littéraires, Paris, n. 26 juin.

1979. Es geht darum mit der Stalinistischer Tradition zu brechen. Prokla, n. 37, p. 127140.

SCHEUERMAN, W. E. 2005. Liberal Democracy and the Social Acceleration of Time. Baltimore : Johns Hopkins University. 
Bob Jessop

Poulantzas claimed that State, Power, Socialism, his last major work, completed the theory of the capitalist type of state that Marx and Engels had left unfinished (1978b). While this immodest but provocative claim certainly merits discussion, it cannot be seriously evaluated in a short essay. Instead I will advance four main arguments. First, Poulantzas developed a major original contribution to the theory of the capitalist type of state that goes well beyond most conventional Marxist analyses and contrasts markedly with studies of the state in capitalist society. Second, he developed a broader approach to the state as a social relation that holds for the capitalist type of state, diverse states in capitalist social formations, and statehood more generally. Third, he adopted both approaches in his own theoretical and historical analyses. And, fourth, his analysis of the current form of the capitalist type of state was highly prescient, with 'authoritarian statism' far more evident now than when he noted this emerging trend in the 1970s. After I have advanced all three arguments, I will also note some basic limitations to Poulantzas's approach to materialist state theory, concluding that State, Power, Socialism should be regarded as a modern classic.

KEYWORDS: Poulantzas; Marxist theory of the State; capitalist State types; authoritarian Statism. 


\section{Bob Jessop}

Poulantzas a déclaré que L'État, le pouvoir, le socialisme, sa dernière grande oeuvre, a accompli la théorie du type capitaliste d'État que Marx et Engels avaient laissé inachevée. Bien que cette imodeste mais provocatrice affirmation mérite certainement un débat, elle ne peut être évaluée sérieusement dans un bref essai. Dans cet article, donc, quatre arguments centraux seront abordés. D’abord, Poulantzas a élaboré une contribution plus importante pour la théorie du type capitaliste d'État qui dépasse les analyses marxistes plutôt conventionnelles et contraste profondément avec les études sur l’État dans la société capitaliste. En second lieu, il a développé une approche plus ample pour l'État comme une relation sociale qui soutient le type capitaliste d’État, plusieurs états dans les formations sociales capitalistes et la condition de l'état en général. En troisième lieu, il a adopté toutes deux approches dans ses propres analyses théoriques et historiques. En quatrième lieu, son 
analyse de la forme actuelle du type capitaliste d’État était vraiment presciente, avec « l’étatisme autoritaire " plus en évidence maintenant qu'au moment où il a noté les traces de son apparition dans les années 1970. Après avoir développé ces arguments, l'article indique aussi quelques limites de base de l'approche de Poulantzas pour la théorie matérialiste d'État, en concluant que L'État, le pouvoir, le socialisme devrait être apperçu comme un classique moderne.

MOTS-CLÉS : Poulantzas ; théorie marxiste d’État ; type capitaliste d’État ; étatisme autoritaire. 